\title{
The Restructuring, Updating and Revision of the Chamber of Mines Rock Mechanics Certificate and its Syllabus
}

\author{
J.V. James Celtis Geotechnical CC, South Africa \\ D.A. Arnold Celtis Geotechnical CC, South Africa
}

\begin{abstract}
The South African mining industry Rock Mechanics Certificates were developed in the 1970s as specialist qualifications for Rock Mechanics Practitioners on South African mines. The mining industry regulated the requirements for these certificates.
\end{abstract}

Changes in the structure of the South African mining industry have led to shortcomings in the certificates. The certificates were originally intended to serve the interests of the South African gold mining and coal mining sectors. This put candidates from other sectors at a disadvantage. South African mining law now prescribes the certificates as a requirement for competent persons in rock engineering. Thus practitioners in all mining sectors need to be certificated.

A revised Rock Mechanics Certificate examination structure was put forward towards the end of 2005 and now forms the basis of the new syllabus.

The structure caters for specialisation amongst Rock Mechanics Practitioners and Rock Engineers in the different mining environments, and reduces restrictions allowing for mobility between mining environments.

The existing old syllabi were reviewed in the light of the proposed new structure, and the new Rock Mechanics Certificate syllabi were generated and compiled.

This approach resulted in the capture of a large amount of learning material for inclusion in the new syllabi. A high degree of uniformity was achieved in the structure of the various parts of the syllabi. A by-product of this process was a simplification of the syllabi and a logical flow of the study material. This will be beneficial for candidates and examiners alike.

The final aim of the exercise was to ensure the development of competent Rock Mechanics and Rock Engineering Practitioners for the complex South African mining industry.

\section{Introduction and background}

The South African mining industry Rock Mechanics Certificates developed informally in the mid- to late1970s (predominantly on deep gold mines). They were originally intended as specialist qualifications that would allow practitioners from a wide variety of backgrounds and disciplines to practice rock mechanics on South African mines. A number of levels of certification quickly evolved, culminating in the three grades of certificate that have been in existence for many years now, viz. the Strata Control Certificate, the Rock Mechanics Certificate and the Advanced Rock Engineering Certificate. Two branches of these certificates evolved to cater for the needs of the gold-mining and coal-mining sectors respectively.

The mining industry regulated the requirements for the certificates by appointing industry incumbents (mainly group rock mechanics engineers) to manage the technical content, while the Chamber of Mines of South Africa provided administrative and financial support. Administration of the Strata Control and Rock Mechanics Certificates was transferred and taken over by Technicon SA (now incorporated within UNISA) in 1997, where a voluntary examinations committee comprised of South African National Institute of Rock Engineering (SANIRE) members currently set and mark examinations associated with the various certificates. Advanced certificate examinations are offered by the mining departments of the University of the Witwatersrand and the University of Pretoria. 


\subsection{Shortcomings of existing certificates}

While the current certificates have served the South African mining industry well over the past thirty years or so, recent changes in the demographics of the industry, and indeed of the country as a whole, have highlighted to an ever-increasing extent the shortcomings of the certificates as they exist today. Perhaps the most serious of these relates to the fact that the certificates were originally primarily intended to serve only the interests of the South African gold mining and coal mining sectors. This puts candidates from other sectors at a distinct disadvantage, and makes life equally difficult for examiners who try to accommodate and be fair to such candidates by setting broad-based exams within the framework and confines of the existing syllabi.

This situation is aggravated by the inclusion in South African mining law of the certificate as a requirement for competent persons in rock engineering. This is in turn referenced in many legally required documents such as Codes of Practice.

Thus practitioners in sectors which previously did not need the certificate now need to obtain it.

During the latter half of 2004 Prof. M.F. Handley (then the Vice-president of SANIRE) authored a proposal for registration of Rock Mechanics Practitioners with the Engineering Council of South Africa (ECSA). He reviewed the job requirements for rock mechanics practitioners as perceived by industry and by government, and evaluated the syllabus content of the rock mechanics certificates in terms ECSA-defined knowledge areas for engineers. It was concluded that there existed a need to restructure the certificates in conjunction with the development of National Qualifications Forum (NQF) / Mines Qualification Authority (MQA) unit standards for rock engineering.

In proposing a new syllabus for the rock mechanics certificate, some of the issues surrounding the certificate, had to be considered.

Although the strata control certificate was originally introduced as a rock mechanics practitioners entry-level examination, it had now become a more broadly based industry strata control qualification and, as such, was no longer a stepping stone to the rock mechanics certificate because of changed standards and requirements.

On the other hand, the rock mechanics certificate was entrenched, and had become the benchmark qualification required for rock mechanics practitioners in South Africa. With the advent of the National Qualifications Authority (NQF) initiatives, the rock mechanics certificate would be incorporated as a recognised qualification for which there would be a set of unit standards, a means of study support, and a means of competency examination.

Since there were several viewpoints over the generic content that candidates should master before they could be allowed to practice as rock mechanics practitioners, the whole structure of the syllabus and of the qualification itself, needed to be revised to suit all parties. There was general agreement that the current providers should carry out syllabus revisions, produce appropriate course content, and continue to examine candidates.

There remained two opposing viewpoints regarding the structure of the rock mechanics certificate examination. At one extreme was the view that all candidates obtain a generic rock mechanics certificate and then specialise in their respective mining environments, and at the other was the view that there should be specialist rock mechanics certificate examinations for individual mining environments. Both of these viewpoints would lead to a restriction of the mobility of rock mechanics practitioners, which in turn would restrict individual freedom of choice and industry flexibility in filling posts.

To reduce this problem and satisfy both viewpoints, it was suggested that the new Rock Mechanics Certificate should consist of six written papers and one practical examination, which would cover all of the major sub-divisions of the discipline. Some of the papers would be generic in nature and would be compulsory, whilst others would be mining environment specific, allowing a selection to be made by candidates according to their individual career requirements and preferences. 


\section{New Certificate Structure}

The suggested rock mechanics certificate examination structure was agreed to by the SANIRE council, towards the end of 2005, and now forms the basis of the new syllabus. The structure is as follows:

\section{Part 1 Basic Rock Mechanics Theory}

A compulsory examination paper for all candidates.

This is a general paper covering basic rock mechanics theory applicable in all types of mining environment. The theoretical rock mechanics knowledge required here is thus of a fundamental nature, and is not specific to any particular type of mining.

\section{Part 2 Basic Rock Mechanics Practice}

A compulsory examination paper for all candidates.

This is a general paper covering basic rock mechanics practice applicable in all types of mining environment. The rock engineering knowledge required here is thus of a fundamental nature, and is not specific to any particular type of mining.

\section{Part 3.1 Hard Rock Tabular Mining}

An optional examination paper, but required for candidates working in hard rock tabular mining environments.

This is a specific mining type paper covering rock mechanics practice applicable in tabular hard rock mining environments at all depths. The rock engineering knowledge required here is thus of a specific nature, relating to the mining of tabular orebodies in hard rock at shallow, moderate and great depth.

\section{Part 3.2 Soft Rock Tabular Mining}

An optional examination paper, but required for candidates working in soft rock tabular mining environments.

This is a specific mining type paper covering rock mechanics practice applicable in tabular soft rock mining environments at all depths. The rock engineering knowledge required here is thus of a specific nature, relating to the mining of tabular orebodies in soft rock at shallow, moderate and great depth.

\section{Part 3.3 Massive Underground Mining (Hard and Soft Rock)}

An optional examination paper, but required for candidates working in massive hard and/or soft rock mining environments.

This is a specific mining type paper covering rock mechanics practice applicable in massive mining environments in hard and soft rock at all depths. The rock engineering knowledge required here is thus of a specific nature, relating to the mining of massive orebodies in hard and soft rock at shallow, moderate and great depth.

\section{Part 3.4 Surface Mining (Hard and Soft Rock)}

An optional examination paper, but required for candidates working in surface hard and/or soft rock mining operations.

This is a specific mining type paper covering rock mechanics practice applicable in surface mining operations in hard and soft rock. The rock engineering knowledge required here is thus of a specific nature, relating to the surface mining of orebodies in hard and soft rock.

\section{Part 4 Rock Mechanics Practical (Surface and Underground)}

A compulsory examination for all candidates, but applicable to the appropriate mining environment of choice, and required to be passed only once regardless of the number of Part 3 papers attempted.

Although this practical examination syllabus is generic in nature, this is a specific mining type oral examination covering the practice of rock mechanics in the applicable mining environment. The rock 
engineering knowledge required here is thus of a specific nature, relating to the mining of orebodies as contemplated in the appropriate Part-3 written examination syllabus.

All candidates will have to pass the examinations associated with Parts 1, 2 and 4, and, depending upon their mining environment, at least one paper from Part 3. (This aspect has yet to be decided, and there is a school of thought that suggests that passes in at least two papers from Part 3 will be required to secure a certificate. Also, the status of certificates awarded to candidates who have passed more than two, or all, of the Part 3 examinations has yet to be decided. There is scope here for awarding specialist and generalist certificates).

The above structure caters for specialisation amongst rock mechanics practitioners and rock engineers in the different mining environments, while at the same time reducing restrictions and allowing for the mobility of rock engineers between mining environments.

\section{Generating the new syllabus}

The authors were requested to review the existing rock mechanics certificate syllabus in the light of the proposed new structure and compile material for the new syllabus. From the outset it was made clear that the new syllabus material would need to conform to South African Qualifications Authority (SAQA) requirements so that the certificate could be registered with the NQF, and be made available to all in the future.

To do this the following course action was followed:

- Research and prepare a comprehensive list of all the various types of actual rock engineering work that is conducted or is required to be conducted on representative mines in each of the proposed mining categories.

- Arising from this information, establish a comprehensive understanding of the types of rock mechanics knowledge and/or expertise that is required to competently conduct this work in each of the mining categories.

- Determine which portions of this learning/knowledge/expertise is generic or common to all mining categories or fields of study and which is unique to each of the mining categories.

- Arising from this, establish a framework that will allow the efficient allocation of subject material into the various syllabi sub-divisions, avoiding as far as possible any duplication of material and study effort across the various categories.

- Attempt as far as possible to ensure that the derived knowledge matrix is outcomes based and will serve as a basis for SAQA compliance.

- Conduct a comprehensive literature search for all available literature and/or study material appropriate to each of the examination fields of study. This will include, but not be limited to, published textbooks, handbooks, research reports, symposia proceedings, Miningtek reports, Safety in Mines Research Advisory Council (SIMRAC) reports, South African Institute of Mining and Metallurgy (SAIMM) journal papers and Association of Mine Managers (AMM) papers and discussions.

- Select the best appropriate material for inclusion in the syllabi.

- Arrange and order the material in terms of the syllabi categories.

- At the same time, evaluate whether the breakdown of examination categories proposed in the SANIRE document represents the best or optimal arrangement.

- Having researched, selected, prioritised and categorised the material, develop each of the various syllabi, having due regard for material already contained in the existing syllabi, expanding, fillingout and adding to this as appropriate.

- Identify specific recommended study material for each examination category and compile this into lists. 
- Identify and approach experts in each of the examination/mining categories with a view to having the revised syllabi and recommended study material lists assessed for relevance and completeness.

- Circulate the draft syllabi and lists of recommended study material to these selected experts in each field represented by the examination/mining categories for their comprehensive review and comment.

- Conduct a workshop for each of the examination categories to discuss, agree upon and finalise draft syllabi and recommended study material lists.

- Prepare, finalise and formally submit the syllabi and study material proposals to SANIRE for ratification.

This approach resulted in the capture of a large amount of learning material for editing, classification and inclusion in the new syllabus. A fundamental part of arranging and allocating all of this material in a systematic and logical fashion within the syllabus was the generation of appropriate headings for each of the parts. These new syllabus headings are as follows:

\section{Part 1 Theory}

- Stress and Strain

- Constitutive Behaviour

- Rock Properties

- Stress in Rock and Rock masses

- Rock mass Properties

- Formulae and Definitions

\section{Part 2 Practice}

- Geotechnical Characteristics

- Rock and Rock mass Behaviour

- Mining Layouts and Mining Layout Design

- Mining Support and Mining Support Design

- Investigation and Evaluation

- Drilling and Blasting

- Legal Compliance

\section{Parts 3.1, 3.2, 3.3 and 3.4 Mining}

- Geotechnical Characteristics

- Rock and Rock mass Behaviour

- Mining Layout Strategies

- Mining Support Strategies

- Investigation Techniques

- Rock Breaking

- Surface and Environmental Effects

- Mining in Difficult Circumstances

\section{Part 4 Practical}

- Geotechnical Characteristics 
- Rock and Rock mass Behaviour

- Mining Layout Strategies

- Mining Support Strategies

- Investigation Techniques

- Rock Breaking

- Surface and Environmental Effects

- Mining in Difficult Circumstances

\subsection{Features of the new syllabus}

It is obvious that a very high degree of uniformity was achieved in the formulation of these headings between the various parts of the syllabus and also that the other objectives of simplifying the syllabus and providing for a logical and systematic flow of the study material was achieved. This was found to be very helpful in organising the syllabus material, and will undoubtedly be equally beneficial for candidates engaged in their studies (which was one of the main objectives of the exercise).

A key objective in generating the new syllabus was to provide comprehensive and balanced coverage of the many facets of the discipline of rock mechanics and rock engineering, while at the same time providing for a candidate-friendly and examiner-friendly syllabus. This balancing act was aimed at eliminating unnecessary repetition while at the same time achieving the requisite degree of subject matter coverage in each of the separate parts of the syllabus.

As it turned out, there is a large degree of commonality and duplication across all of the parts, with some subject matter being covered in many of the parts, but to varying degrees of emphasis and detail as appropriate. For example: rock mass classification is a common and important component in all of the mining sub-divisions. It is therefore afforded comprehensive inclusion in the Practice syllabus (which is a compulsory paper), and also appears at appropriate levels of detail in the four Mining parts. On the other hand, seismicity is an issue predominantly (but not exclusively) related to deep, hard rock situations. It is therefore dealt with in detail in the Hard Rock Tabular syllabus, while being touched on only in broad general terms in the compulsory Practice syllabus. Other examples of this approach are to be found throughout the syllabus, for example in the sections pertaining to modelling, monitoring, and so on.

In terms of critical outcomes, examinations associated with the syllabus are aimed at testing the candidate's abilities in the six cognitive levels of knowledge, comprehension, application, analysis, synthesis and evaluation. Thus when being examined on the topics detailed in the syllabus, candidates will be required to demonstrate their capacity for comprehending and understanding the general rock engineering principles involved, and applying these to solving real world mining problems. Further, candidates will be required to demonstrate that they are able to apply fundamental scientific knowledge, comprehension and understanding to predict the behaviour of rock materials in real world mining environments; and to perform creative procedural design and synthesis of mine layouts and support systems to control and influence rock behaviour and rock failure processes using engineering methods, as well as an understanding of the uses of computer packages for the computation, modelling, simulation, and evaluation of mining layouts. Candidates will also be required to demonstrate their abilities in communicating, explaining and discussing the reasoning, methodology, results and ramifications of all the above aspects in a professional manner at all levels.

The syllabus assumes that candidates have prior learning and a good understanding of the field of fundamental mechanics appropriate to the respective parts of the syllabus, and have prior learning and a good understanding of the meaning, application and manipulation of terms, definitions, formulae and conventions appropriate to the respective parts of the syllabus (as outlined in the relevant sections of the syllabus documentation). The underlying physics, engineering science, basic science and mathematics required for the qualification will be defined shortly during the course of generating NQF unit standards for the rock mechanics certificate. These will conform to tertiary level requirements for engineering, and will have to be listed for the benefit of those candidates without formal tertiary education. 
While candidates are directed by the syllabus to a variety of study and reference sources, including published textbooks and handbooks, symposia proceedings and research reports, institute journals and association papers, an overall objective was to optimise the required study and reference material to the least number of most comprehensive and up-to-date sources. This task was made easy by the recent appearance of highquality handbooks and textbooks in nearly all of the mining categories covered by the syllabus. These publications have been funded by industry through the auspices of the Safety in Mines Research Advisory Committee (SIMRAC), and the facilitators and authors of these publications are to be commended for their valuable contribution to the advancement of education and training in the fields of rock mechanics and rock engineering. The primary objective of the syllabus and examination system has always remained to help ensure the development of competent rock mechanics and rock engineering practitioners.

\subsection{Collaborator and industry input}

The very best expertise the industry has to offer in each and every theoretical and practical component of the discipline was approached to either champion or to provide specialist input into, and critique of, the various sections of the syllabus. Very useful comment and comprehensive feedback was forthcoming from these experts, and this was edited and incorporated into the final draft.

The completed draft syllabus was made available to the members of SANIRE council, and following a series of formal presentations to SANIRE council, the syllabus was ratified and accepted, and was favourably received.

Finally, by way of further publicising and promoting the new syllabus, presentations were made at the technical meetings of a number of the SANIRE branches that serve the various mining regions.

\section{The way forward}

The implementation of these changes to the exam structure and the revised content will be implemented in the second half of 2007. The Chamber of Mines as an employer body retains the title to the certificate, and this has an advantage as the certificate is thus viewed as self regulation by the industry. SANIRE however will now be responsible for the examination committee consisting of Examiners, Moderators and representatives of interested sectors. A further factor is that the Certificate may well be part of the qualification for Professional Engineer status for Rock Engineering Practitioners, which is currently being discussed.

It is thought that persons with existing certificates will retain them with metalliferous certificates being equivalent to a certificate with either paper 3.1, 3.3 or even 3.4 if the practitioner is working in those fields. Those with coal certificates will be equivalent to certificates with 3.2, 3.3 or 3.4. For candidates with parts of the certificate credit will be probably given as follows:-

- $\quad$ Theory - Paper 1

- $\quad$ Applications Coal - Paper 3.2, 3.3 or 3.4

- $\quad$ Applications Metalliferous - Paper 3.1, 3.3 or 3.4

- General - Paper 2

- Practical - Practical

\section{Acknowledgements}

Many people have made valuable contributions, both in the present and in the past, to the compilation of the new rock mechanics syllabus. The authors, and indeed the entire South African Rock Engineering fraternity, thank them. 